\title{
Dopamine Alters AMPA Receptor Synaptic Expression and Subunit Composition in Dopamine Neurons of the Ventral Tegmental Area Cultured with Prefrontal Cortex Neurons
}

\author{
Can Gao and Marina E. Wolf \\ Department of Neuroscience, The Chicago Medical School at Rosalind Franklin University of Medicine and Science, North Chicago, Illinois 60064
}

Excitatory synapses onto dopamine (DA) neurons of the ventral tegmental area (VTA) represent a critical site of psychostimulantinduced synaptic plasticity. This plasticity involves alterations in synaptic strength through AMPA receptor (AMPAR) redistribution. Here, we report an in vitro model for studying regulation of AMPAR trafficking in DA neurons under control conditions and after elevation of DA levels, mimicking cocaine exposure. We used cocultures containing rat VTA neurons and prefrontal cortex (PFC) neurons from enhanced cyan fluorescent protein-expressing mice. In VTA-PFC cocultures, $\mathrm{D}_{1}$ receptor activation $(10 \mathrm{~min})$ increased synaptic and nonsynaptic glutamate receptor subunit 1 (GluR1) and GluR2 surface expression on DA neurons. NMDA or AMPA receptor antagonists blocked this effect, and it was not observed in pure VTA cultures, suggesting that DA agonists acted on $\mathrm{D}_{1}$ receptors on PFC neurons, altering their excitatory transmission onto VTA DA neurons and, thus, influencing AMPARs. To mimic the longer elevation in extracellular DA levels produced by systemic cocaine, cocultures were incubated with DA for $1 \mathrm{~h}$. Synaptic GluR1 was increased $24 \mathrm{~h}$ later, reminiscent of the increased AMPA/NMDA ratio at excitatory synapses onto VTA DA neurons $24 \mathrm{~h}$ after cocaine injection (Ungless et al., 2001). In contrast, GluR2 was unchanged. Analysis of colocalization of surface GluR1-3 labeling suggested that control DA neurons express a substantial number of GluR1/2, GluR2/3, and homomeric GluR1 receptors and that the increase in surface AMPARs $24 \mathrm{~h}$ after DA exposure may in part reflect increased GluR1/3-containing receptors. These results help define the cellular basis for plasticity underlying the development of behavioral sensitization.

Key words: behavioral sensitization; $\mathrm{D}_{1}$ receptor; $\mathrm{D}_{2}$ receptor; glutamate receptors; $\mathrm{NMDA}$ receptor; receptor trafficking

\section{Introduction}

Dopamine (DA) neurons of the ventral tegmental area (VTA), which project to the nucleus accumbens, prefrontal cortex (PFC), and other corticolimbic regions, mediate responses to rewards and reward-predicting stimuli (Schultz, 2007). An important source of excitatory drive to these neurons is provided by glutamate inputs, which arise from many different brain regions including the PFC (Carr and Sesack, 2000; Omelchenko and Sesack, 2005, 2007; Geisler et al., 2007).

The development of behavioral sensitization, an animal model for intensification of drug "wanting", requires a transient increase in excitatory drive to VTA DA neurons (Wolf, 1998). This is attributable in part to long-term potentiation (LTP) at excitatory synapses onto VTA DA neurons (Kauer, 2004; Wolf et al., 2004). This was initially suggested by extracellular recording studies showing increased sensitivity of VTA DA neurons to glutamate agonists after psychostimulant exposure (White et al.,

Received June 27, 2007; revised Nov. 14, 2007; accepted Nov. 15, 2007.

This work was supported by National Institute on Drug Abuse Grant DA015835 and Independent Scientist Award DA00453 (M.E.W.). We thank Drs. Marjorie Ariano and Greg Kapatos for providing antibodies. We also thank Drs. Xiu Sun, Carrie Ferrario, Amy Boudreau, and Marjorie Ariano for helpful comments on experiments and this manuscript.

Correspondence should be addressed to Marina E. Wolf at the above address. E-mail: marina.wolf@rosalindfranklin.edu.

DOI:10.1523/JNEUROSCI.2925-07.2007

Copyright $\odot 2007$ Society for Neuroscience 0270-6474/07/2714275-11\$15.00/0
1995; Zhang et al., 1997). Direct evidence for LTP was first provided by Ungless et al. (2001), who demonstrated that a single cocaine injection induced LTP of AMPA receptor (AMPAR) currents, measured as an increase in the AMPA/NMDA ratio, at excitatory synapses onto VTA DA cells.

Temporal aspects of psychostimulant-induced synaptic potentiation have been well characterized. An increased AMPA/ NMDA ratio was detected as early as $2 \mathrm{~h}$ after amphetamine injection (Faleiro et al., 2004). Regardless of whether rats received a single or multiple cocaine injections, the AMPA/NMDA ratio remained elevated $5 \mathrm{~d}$, but not $10 \mathrm{~d}$ after the last exposure (Borgland et al., 2004). After longer withdrawals (10-15 d), presynaptic adaptations, triggered by BDNF, may account for more persistent increases in the sensitivity of VTA synapses to activityinduced potentiation ( $\mathrm{Pu}$ et al., 2006).

Cellular mechanisms underlying the cocaine-induced increase in the AMPA/NMDA ratio are poorly understood. However, an increase in this ratio can reflect insertion of new glutamate receptor subunit 1 (GluR1)-containing AMPARs into synapses (Malinow and Malenka, 2002). Consistent with this, GluR1 knock-out mice do not develop cocaine-induced synaptic potentiation, although they do develop behavioral sensitization; other mechanisms may compensate in the absence of GluR1 (Dong et al., 2004). Mechanisms underlying AMPAR trafficking have been well studied in hippocampus, cerebellum, and cortex 
(Bredt and Nicoll, 2003; Collingridge et al., 2004; Cull-Candy et al., 2006; Derkach et al., 2007), but little is known about how synaptic AMPAR levels are regulated within DA neurons. One possibility is that elevated DA levels, produced by psychostimulants, are directly responsible for increasing AMPAR synaptic insertion and thus increasing the AMPA/NMDA ratio. We and others have shown that DA receptors regulate GluR1 distribution in several addiction-related brain regions, such as nucleus accumbens (Chao et al., 2002a,b; Mangiavacchi and Wolf, 2004), PFC (Sun et al., 2005), and hippocampus (Smith et al., 2005; Gao et al., 2006). To study the VTA, we developed a VTA-PFC coculture system in which rat VTA neurons are grown with PFC neurons from enhanced cyan fluorescent protein-expressing mice. This system enables us to study AMPAR synaptic targeting in VTA DA neurons because the PFC neurons restore glutamate synapses onto VTA DA neurons.

\section{Materials and Methods}

Animals. All animal use procedures were in strict accordance with the National Institutes of Health Guide for the Care and Use of Laboratory Animals and were approved by the Institutional Animal Care and Use Committee of Rosalind Franklin University of Medicine and Science. Pregnant Sprague-Dawley rats (Harlan, Indianapolis, IN; Zivic Miller, Pittsburgh, PA), obtained at 19-20 d of gestation, were housed individually in breeding cages. One-day-old [postnatal day 1 (P1)] offspring were used to prepare VTA cultures. P2-P3 pups were used to prepare astrocyte cultures. PFC cells were obtained from P1 homozygous enhanced cyan fluorescent protein (ECFP)-expressing mice [strain, B6.129 (ICR)-Tg (ACTB-ECFP) 1Nagy/J; Jackson Laboratory, Bar Harbor, ME] which were bred in house.

Postnatal VTA cultures. The medial portion of the ventral midbrain, which contains the VTA, was isolated and dissociated with papain (20-25 U/ml; Worthington Biochemical, Lakewood, NJ) at $37^{\circ} \mathrm{C}$ for 40-50 min. Cells were plated on coverslips coated with poly-D-lysine $(100 \mu \mathrm{g} / \mathrm{ml}$; Sigma, St. Louis, MO) in 24-well culture plates at a density of 20000 cells/well and grown in astrocyte-conditioned NeuroBasal medium (Invitrogen, Carlsbad, CA; 2 mm GlutaMax, 0.5\% gentamicin and $2 \%$ B27). One-half of the medium was replaced with identical medium every $4 \mathrm{~d}$. Cultures were used for experiments between 10 and $12 \mathrm{~d}$ in vitro (DIV).

Postnatal VTA-PFC cocultures. The medial PFC of ECFP-expressing P1 mice was isolated and dissociated with papain at $37^{\circ} \mathrm{C}$ for $20 \mathrm{~min}$. $\mathrm{PFC}$ cells were plated on coverslips at a density of 30000 cells/well. Seven to $9 \mathrm{~d}$ later, VTA-enriched midbrain was dissected from P1 rats and dissociated (see above, VTA cultures). Dissociated midbrain cells were then seeded on PFC cells at a density of 20,000 cells/well. These relative amounts of PFC and midbrain cells resulted in cocultures with PFC and midbrain cells in close proximity, but cell density was still low enough for optimal image analysis. The VTA-PFC cocultures were grown in Neurobasal medium supplemented with $2 \mathrm{~mm}$ GlutaMax, $0.5 \%$ gentamicin and $2 \%$ B27. One-half of the medium was replaced with this Neurobasal growth medium every $4 \mathrm{~d}$. Cultures were used for experiments $10 \mathrm{~d}$ after seeding VTA cells.

Astrocyte cultures. The cortex from P2-P3 rats was isolated and dissociated as described previously (Mangiavacchi and Wolf, 2004). The cells were plated in a poly-D-lysine-coated flask with insulin $(10 \mu \mathrm{g} / \mathrm{ml}$; Sigma) supplemented minimal essential media (MEM; Invitrogen; $10 \%$ FBS, 2 mm GlutaMax, 0.5\% gentamicin, and $0.35 \%$ glucose). After $1 \mathrm{~h}$ incubation, cultures were rinsed with ice-cold MEM to selectively wash off other cell types and leave astrocytes attached to the culture flask. Then, insulin-supplemented MEM was added. Media was replaced every 5-7 d with insulin-supplemented MEM (except, the 10\% FBS was decreased to $2 \%$ FBS). The NeuroBasal medium (2 mm GlutaMax, $0.5 \%$ gentamicin) was conditioned with astrocyte cultures for 18-24 h before use. Then the conditioned medium was collected and B27 was added for the VTA cultures.

Immunocytochemistry. Cell-surface GluR1 was labeled by incubating live cultures with polyclonal antibody to the extracellular N-terminal domain of GluR1 (amino acids 271-285, RTSDSRDHTRVDWKR; 1:10; Calbiochem, La Jolla, CA) in NeuroBasal growth medium for $15 \mathrm{~min}$ at $37^{\circ} \mathrm{C}$. Cells were then washed with media (twice) and PBS (twice), fixed with $4 \%$ formaldehyde in PBS containing 4\% sucrose for $15 \mathrm{~min}$ at room temperature (RT), blocked with 5\% donkey serum in PBS for $2 \mathrm{~h}$ and incubated with donkey anti-rabbit secondary antibody conjugated to Cy3 (1:500; Jackson ImmunoResearch, West Grove, PA) at RT for $1 \mathrm{~h}$ under nonpermeant conditions. Then, cells were permeabilized with $0.1 \%$ Triton X-100 in PBS for 15 min, blocked with 5\% donkey serum in PBS for $1 \mathrm{~h}$, and incubated with monoclonal antibody to the synaptic marker synaptobrevin/VAMP 2 (SB, 1:1000; Synaptic Systems, Göttingen, Germany) overnight at $4^{\circ} \mathrm{C}$ followed by donkey anti-mouse secondary antibody conjugated to Alexa 488 (1:1000; Invitrogen) for $1 \mathrm{~h}$ at RT. For double staining of surface GluR2 and synaptophysin, live cells were labeled with mouse monoclonal antibody recognizing the extracellular N-terminal domain of GluR2 (amino acids 175-430, MAB397; 1:20; Millipore, Billerica, MA) for $15 \mathrm{~min}$ at $37^{\circ} \mathrm{C}$, followed by donkey antimouse secondary antibody conjugated to Alexa 488 (1:1000). Then the cells were incubated with polyclonal antibody to the synaptic marker synaptophysin (1:500; Zymed, Carlsbad, CA) under permeant conditions followed by donkey anti-rabbit secondary antibody conjugated to Cy3 (1:500).

For double staining of cell surface GluR1 and cell surface GluR2, polyclonal antibody recognizing the extracellular N-terminal domain of GluR1 and mouse monoclonal antibody recognizing the extracellular $\mathrm{N}$-terminal domain of GluR2 were added in Neurobasal medium to live cells at $37^{\circ} \mathrm{C}$ for $15-20 \mathrm{~min}$. Cells were then fixed, blocked as in the GluR1 staining protocol (above) and incubated with secondary antibodies (donkey anti-rabbit conjugated to Cy3, 1:500; donkey anti-mouse conjugated to Alexa 488, 1:1000) for $1 \mathrm{~h}$ at RT under nonpermeant conditions. For double staining of cell surface GluR1 and cell surface GluR3, mouse monoclonal antibody recognizing the extracellular N-terminal domain of GluR3 (MAB5416; 1:30; Millipore) was used instead of GluR2 antibody with the same protocol.

In experiments involving drug exposure before AMPAR subunit staining, cells were washed twice in media after drug exposure, incubated with an AMPAR subunit antibody (15-20 min), washed in media (twice) and PBS (twice), and then fixed with formaldehyde. Thus, fixation took place $\sim 20-25$ min after the end of drug exposure.

For tyrosine hydroxylase (TH) staining, the cultures were fixed using $4 \%$ formaldehyde in PBS containing 4\% sucrose for $15 \mathrm{~min}$, blocked with Dulbecco's PBS (DPBS) containing 0.3\% Triton X-100 and 2\% donkey serum for at least $2 \mathrm{~h}$ at RT, and incubated with a mouse monoclonal anti-TH antibody (1:1000; kindly provided by Dr. Greg Kapatos, Wayne State University, Detroit, MI) in blocking solution overnight at $4^{\circ} \mathrm{C}$. Cells were subsequently incubated with donkey anti-mouse secondary antibody conjugated to Alexa 488 (1:2000; in blocking solution) for $1 \mathrm{~h}$ at RT. For double staining of cell surface dopamine receptors and TH, live cells were labeled with polyclonal antibodies recognizing the extracellular domain of $D_{1}, D_{2}$, or $D_{5}$ receptors (kindly provided by Dr. Marjorie Ariano, Rosalind Franklin University of Medicine and Science, Chicago, IL) at RT for $30 \mathrm{~min}$. Then the cells were fixed and stained with donkey antirabbit secondary antibody conjugated to Cy3 (1:500) at RT for $1 \mathrm{~h}$. TH staining was performed as described above.

Data analysis. Images were acquired and analyzed as described previously (Sun et al., 2005; Gao et al., 2006) with an imaging system consisting of a Nikon (Tokyo, Japan) inverted microscope, ORCA-ER digital camera (Hamamatsu, Bridgewater, NJ), and MetaMorph software (Universal Imaging, Downingtown, PA). All experimental groups to be compared were run simultaneously using cells from the same culture preparation and all images were taken using identical acquisition parameters. It was not possible to costain for $\mathrm{TH}$ in most experiments, but we attempted to selectively analyze DA neurons by selecting medium-sized fusiform neurons with processes that emerged from opposite sides of the soma along its long axis (see Results for more discussion). For each experimental group, we selected $\sim 6$ putative $\mathrm{TH}$ positive $\left(\mathrm{TH}^{+}\right)$neurons per well from at least four different wells. One $30 \mu \mathrm{m}$ process segment located about one-half soma diameter from the soma was chosen 
Phase

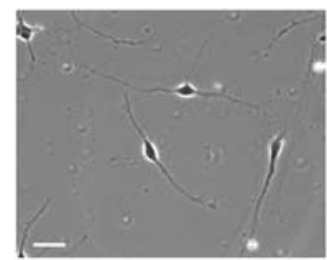

DIV 5
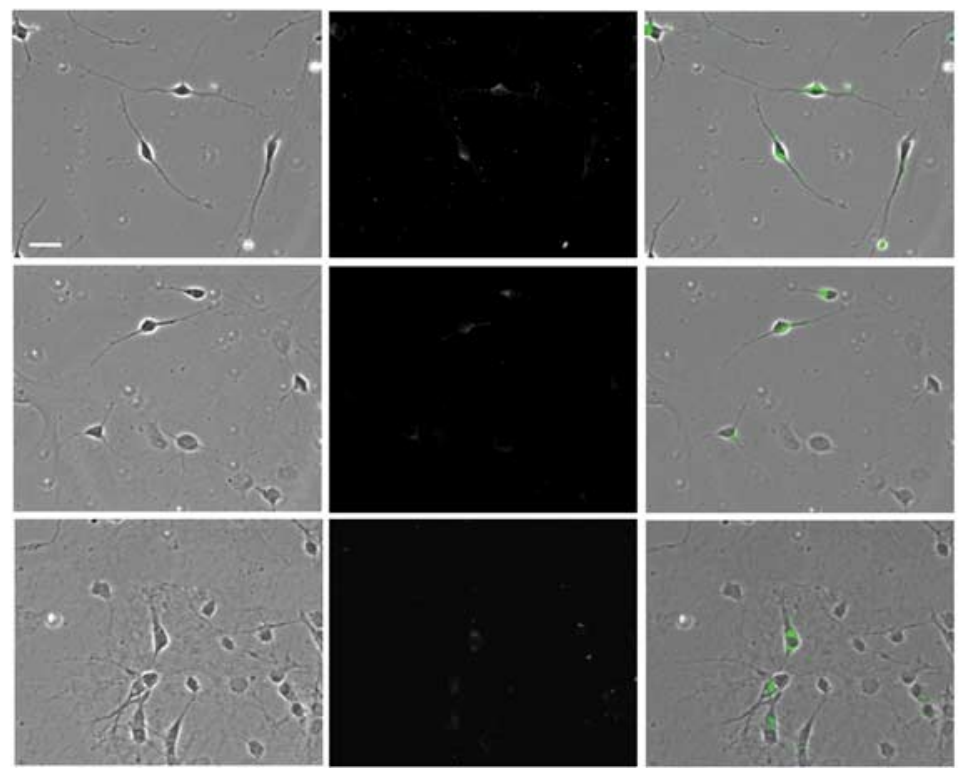

B
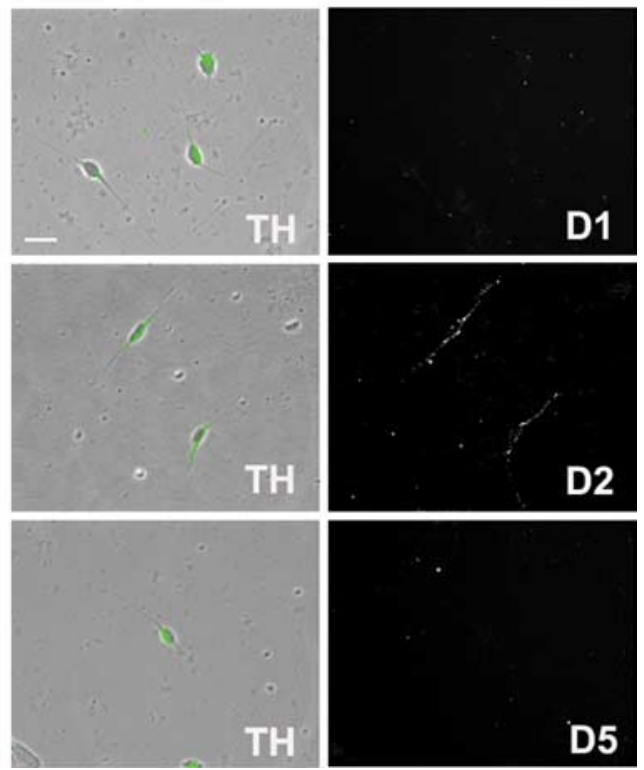

Figure 1. Characterization of DA neurons in VTA cultures prepared from P1 rats. $A$, DA neurons were identified based on TH staining. After 5 , 10, or 14 DIV, cultures were permeabilized and incubated with TH antibody followed by secondary antibody conjugated to Alexa 488 . $B$, DA neurons in VTA cultures express $D_{2}$ receptors, but not $D_{1}$ or $D_{5}$ receptors on the cell surface. Cell surface DA receptors were labeled by incubating live cells ( $10 \mathrm{DIV}$ ) with polyclonal antibodies recognizing the extracellular $\mathrm{N}$-terminal of the $\mathrm{D}_{1}, \mathrm{D}_{2}$, or $\mathrm{D}_{5}$ receptor, followed by secondary antibody conjugated to Cy3. Then, cells were permeabilized and stained for TH followed by secondary antibody conjugated to Alexa 488 . Left, Green indicates TH ${ }^{+}$neurons; right, cell surface DA receptor staining. Scale bars: $20 \mu \mathrm{m}$.

for analysis under phase contrast imaging, to avoid the possibility of experimenter bias based on the intensity of fluorescence staining. The soma was excluded from all measurements. For each image, the total area of cell surface AMPAR staining was measured automatically using a threshold set at least two times higher than the average background fluorescence in processes of untreated control cells. The area of synaptobrevin or synaptophysin staining was defined using the same approach. Synaptic GluR1 area was defined as the area of GluR1 staining (in arbitrary units) that overlapped with synaptobrevin staining. Nonsynaptic GluR1 area was defined as the area of GluR1 staining (in arbitrary units) that did not overlap with synaptobrevin staining. Finally, we determined the fraction of total synaptobrevin staining that overlapped with GluR1 staining (area of synaptobrevin and GluR1 colocalization/total synaptobrevin area). This provides a measure of the fraction of total synaptic area that contains GluR1. The same approaches were used for analysis of GluR2 and synaptophysin double staining experiments. Results from each experimental group were normalized to untreated control cells. All values refer to mean \pm SEM. Independent group $t$ tests were used for comparisons between two experimental groups. For multiple groups, ANOVA was used, followed, when appropriate, by a Dunn's test (significance set at $p<0.05 ; n$, number of cells analyzed).

Drugs. CNQX sodium salt, D-(-)-2-amino-5-phosphonopentanoic acid (APV), dopamine hydrochloride, quinpirole dihydrochloride, $R$-(+)-7-chloro-8-hydroxy-3-methyl-1-phenyl2,3,4,5-tetrahydro-1H-3-benzazepine hydrochloride (SCH 23390), (土)-6-chloro-7,8-dihydroxy-1-phenyl-2,3,4,5-tetrahydro- $1 \mathrm{H}$-3benzazepine hydrobromide (SKF 81297), Sp-Adenosine 3',5'-cyclic monophosphorothioate triethylammonium salt hydrate (SpcAMPS), and $3^{\prime}, 5^{\prime}$-cyclic monophosphorothioate triethylammonium salt (RpcAMPS) were purchased from Sigma and were dissolved in water.

\section{Results}

Tyrosine hydroxylase positive neurons in pure VTA cultures express cell surface $D_{2}$ receptors, but not $D_{1}$ or $D_{5}$ receptors A specific approach for visualizing DA neurons is to use $\mathrm{TH}$ immunocytochemistry (Kapatos and Hirayama, 1994). To characterize expression of DA neurons in our postnatal VTA cultures, we counted $\mathrm{TH}^{+}$neurons after 5,10 , or 14 DIV. Based on analysis of $\sim 400$ cells from randomly selected fields in four wells, we determined that $\mathrm{TH}^{+}$neurons comprised $\sim 25 \%$ of total cells at DIV 5 and $\sim 15 \%$ at DIV 10 , but $<10 \%$ at DIV14 (Fig. $1 A$ ). Consistent with this decline over time, Rayport et al. (1992) reported that $24 \%$ of neurons in postnatal VTA cultures from P5-P7 rat pups were $\mathrm{TH}^{+}$after $0.5 \mathrm{DIV}$. Cultures from postnatal neurons are considerably more enriched than cultures from embryonic neurons, which typically contain $<5 \% \mathrm{TH}^{+}$neurons ( $\mathrm{di}$ Porzio et al., 1980; Heyer, 1984; Chiodo and Kapatos, 1987; Silva et al., 1988; Rayport et al., 1992; Gross et al., 1999; Lotharius et al., 1999), probably because a more selective dissection is possible in the postnatal brain (Rayport et al., 1992). Many of the cells lacking detectable TH immunoreactivity are likely to be GABA neurons (Kalivas, 1993).

It was not possible to costain for $\mathrm{TH}$ in most experiments, because all available fluorophores were used (cyan for PFC cells, red and green for an AMPAR subunit and a synaptic marker or a pair of AMPAR subunits), so we attempted to selectively analyze putative DA neurons based on morphological criteria. We observed four types of $\mathrm{TH}^{+}$cells in VTA cultures, in the same order of abundance described by Rayport et al. (1992). The two most abundant classes were (1) large, oval, multipolar cells with an eccentric nucleus, and (2) medium-sized, fusiform, bipolar cells. The first cell type (large, oval, multipolar) was not analyzed because process thickness, length and number were so irregular that we had difficulty defining "rules" to select comparable process segments for analysis. Instead, we focused on the second type because $\sim 90 \%$ of neurons with fusiform bipolar morphology were $\mathrm{TH}^{+}(\sim 96 \%$ at DIV $5, \sim 91 \%$ at DIV $10, \sim 88 \%$ at DIV 14 ; based on $\sim 400$ cells from four wells) and such cells represent a very common type of $\mathrm{TH}^{+}$neuron in the adult rat VTA (Grace and Onn, 1989). As was found when counting total $\mathrm{TH}^{+}$cells (above), the number of fusiform bipolar neurons declined signif- 
icantly during the first 2 weeks in vitro ( $\sim 20 \%$ of total cells on DIV $5 ; \sim 5 \%$ on DIV 10 ; $\sim 2 \%$ on DIV 14 ; based on $\sim 400$ cells from four wells).

DA neurons in the adult rat VTA have been shown to express $\mathrm{D}_{2}$ receptors (Sesack et al., 1994) and $\mathrm{D}_{5}$ receptors (Ciliax et al., 2000; Khan et al., 2000), but not $\mathrm{D}_{1}$ receptors (Yung et al., 1995). In our live cell labeling studies of pure VTA cultures, using antibodies that recognize the extracellular domains of these DA receptors, we did not observe $D_{1}$ or $\mathrm{D}_{5}$ receptors on the surface of $\mathrm{TH}^{+}$neurons, whereas robust labeling for $\mathrm{D}_{2}$ receptors was observed on the surface of the soma and processes (Fig. $1 B$ ). It is possible that the discrepancy regarding $D_{5}$ receptors is related to developmental age.

In the experiments described below, we used DA agonists that stimulate either $\mathrm{D}_{1}$ class $\left(\mathrm{D}_{1} / \mathrm{D}_{5}\right)$ or $\mathrm{D}_{2}$-class $\left(\mathrm{D}_{2} / \mathrm{D}_{3} / \mathrm{D}_{4}\right) \mathrm{DA}$ receptors, but do not distinguish between members of each class. For simplicity, we will use the terms " $D_{1}$ " and " $D_{2}$ " to refer to effects that may involve the $\mathrm{D}_{1}$-class or $\mathrm{D}_{2}$ class of DA receptors. In pure VTA cultures, it is likely that $\mathrm{D}_{5}$ and $\mathrm{D}_{2}$ receptors mediate effects of these drug classes, respectively. However, $\mathrm{D}_{1}, \mathrm{D}_{3}$, and $\mathrm{D}_{4}$ receptors are also highly expressed in the PFC (Bentivoglio and Morelli, 2005), so these receptors may contribute to DA agonist effects in VTA-PFC cocultures.

DA neurons in pure VTA cultures express GluR1 mainly at extrasynaptic sites

In all experiments from this point forward, we could not evaluate $\mathrm{TH}$ staining because this was not compatible with other immunocytochemical procedures (see above). Therefore, the term "DA neuron" will be used to refer to cells with the morphology of $\mathrm{TH}^{+}$ neurons. To determine an appropriate culture age for subsequent experiments, expression of surface GluR1 and the synaptic marker synaptobrevin were measured on the processes of DA neurons after 5, 10, or 14 DIV. Live cells from each time-point were incubated with antibody to the extracellular domain of GluR1 and then stained for synaptobrevin after permeabilization. Figure $2 \mathrm{~A}$ depicts representative images of GluR1 and synaptobrevin staining at DIV 10. Surface GluR1 and synaptobrevin staining were quantified by measuring the average area of GluR1or synaptobrevin-positive puncta per $30 \mu \mathrm{m}$ of neuronal process on DIV 5, 10, and 14. Surface GluR1 was maximal by DIV 10 whereas synaptobrevin staining continued to increase (Fig. 2 B). Taking these results into account, along with the decrease in number of $\mathrm{TH}^{+}$neurons between DIV 5 and 14 (above), we performed subsequent experiments between 10 and 12 DIV. Analysis of colocalization of synaptobrevin and surface GluR1 staining indicated that DA neurons express GluR1 mainly at extrasynaptic sites on DIV 10 (Fig. 2A). This was expected, because the majority of synapses in pure VTA cultures are likely to be dopaminergic or GABAergic rather than glutamatergic (see Discussion). It is notable that surface GluR1 levels on VTA DA neurons were considerably lower than other cell types we have examined (Chao et al., 2002b; Sun et al., 2005; Gao et al., 2006).
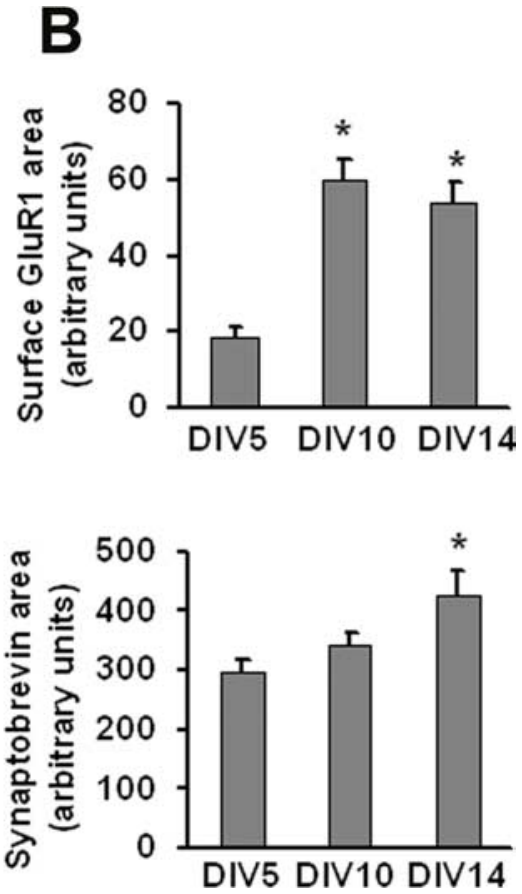

Figure 2. DA neurons in VTA cultures express cell surface GluR1 mainly at extrasynaptic sites. Cell surface GluR1 was labeled by Error bars indicate SEM in this and all subsequent figures.

DA agonists do not alter GluR1 surface expression by DA neurons in pure VTA cultures

To determine whether DA agonists alter GluR1 surface expression in DA neurons, live VTA cultures were incubated with media (control group), the $\mathrm{D}_{2}$ agonist quinpirole (1 or $10 \mu \mathrm{M}$ ), the $\mathrm{D}_{1}$ agonist SKF $81297(1$ or $10 \mu \mathrm{M})$ or DA $(1$ or $10 \mu \mathrm{M})$ for $10 \mathrm{~min}$. None of these treatments altered GluR1 surface expression (Fig. 3). Lack of response to the $D_{1}$ agonist is not surprising given lack of detectable $\mathrm{D}_{1}$ or $\mathrm{D}_{5}$ receptor expression on the surface of VTA DA neurons in our cultures. Lack of response to DA or quinpirole indicates that $\mathrm{D}_{2}$ autoreceptors are not coupled to signaling pathways that regulate AMPAR distribution.

Activation of PKA increases GluR1 surface expression by DA neurons in pure VTA cultures

We showed previously that activation of protein kinase A (PKA) increases the rate of GluR1 externalization onto the surface of nucleus accumbens medium spiny neurons (Mangiavacchi and Wolf, 2004), PFC pyramidal neurons (Sun et al., 2005) and hippocampal pyramidal neurons (Gao et al., 2006). Similarly, we found that SpcAMPS (10 $\mu \mathrm{M}, 10 \mathrm{~min})$, a membrane-permeable PKA activator, increased GluR1 surface expression on DA neurons in pure VTA cultures. This effect was blocked by RpcAMPS $(10 \mu \mathrm{M})$, a membrane-permeable PKA inhibitor (Fig. 4).

Coculture with PFC neurons increases synapse number and synaptic GluR1 incorporation in VTA DA neurons

While a small number of VTA neurons use glutamate as a transmitter, VTA neurons in the intact brain receive important glutamate projections from other brain regions, including the PFC, 


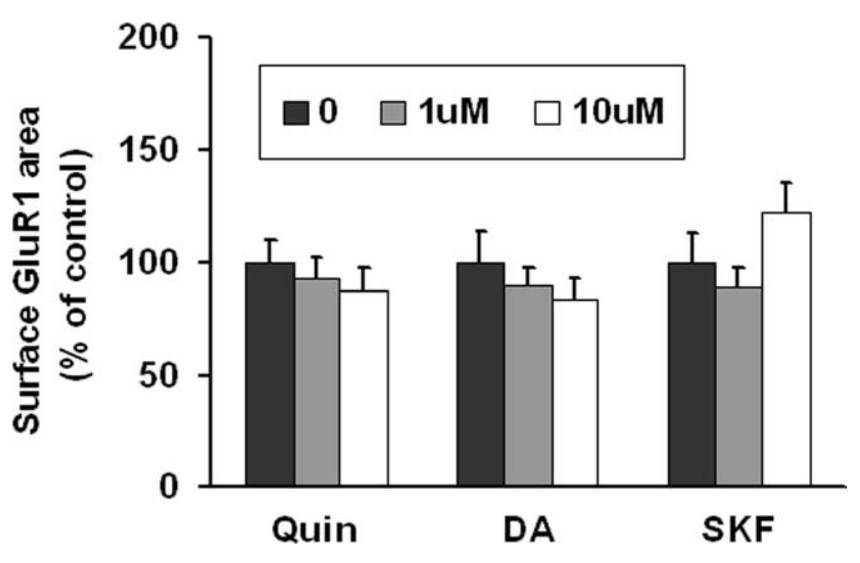

Figure 3. DA agonists have no effect on GluR1 surface expression on DA neurons in VTA cultures. VTA cultures were incubated with media (control group), the $D_{2}$ receptor agonist quinpirole (Quin; $1 \mu \mathrm{m}, 10 \mu \mathrm{m}$ ), DA (1 $\mu \mathrm{m}, 10 \mu \mathrm{m}$ ), or the $\mathrm{D}_{1}$ receptor agonist SKF 81297 (SKF; $1 \mu \mathrm{m}, 10 \mu \mathrm{m}$ ) for $10 \mathrm{~min}$. Then surface GluR1 was labeled by incubating live cells with antibody recognizing the extracellular $\mathrm{N}$-terminal domain of GluR1, followed by $\mathrm{Cy} 3$ conjugated secondary antibody. DA agonist-treated groups were not significantly different from the control group $(n=18-34 ;$ ANOVA, $p>0.05)$. Results are presented as the mean area of GluR1 staining, normalized to the control group.

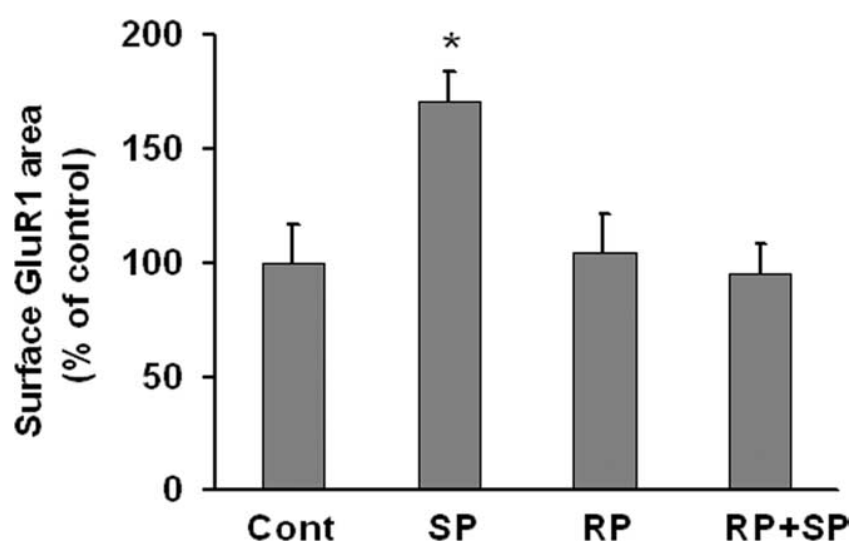

Figure 4. PKA activation increases GluR1 surface expression by DA neurons in VTA cultures. Quantification of surface GluR1 expression after incubation with media (control group), the PKA activator SpcAMPS (SP; $10 \mu \mathrm{M}, 10 \mathrm{~min}$ ), the PKA inhibitor RpcAMPS (RP; $10 \mu \mathrm{M}, 10 \mathrm{~min}$ ), or RP + SP (after 5 min preincubation with RpcAMPS, SpcAMPS was added for 10 min). SpcAMPS significantly increased surface GluR1 compared with the control group ( $n=18-33$; Dunn's test, $\left.{ }^{*} p<0.05\right)$. RpcAMPS had no effect on basal GluR1 surface expression, but completely blocked the effect of SpcAMPS.

that are lacking in pure VTA cultures (see Discussion). To restore extrinsic excitatory synaptic input to VTA DA neurons, we established a VTA-PFC coculture system by plating PFC neurons from ECFP transgenic mice with VTA neurons from rats that do not express ECFP. Virtually all neurons from ECFP mice express ECFP. Accordingly, in VTA-PFC cocultures, cells with the morphology of PFC neurons expressed ECFP (Fig. 5A, blue fluorescent cells) whereas cells with the morphology of VTA DA neurons did not (Fig. 5A, nonfluorescent cells). Thus, this coculture system enables us to easily distinguish VTA cells from PFC cells under fluorescence microscopy.

First, we studied DA receptor surface expression on DA cells in VTA-PFC cocultures and found that $\mathrm{D}_{2}$ but not $\mathrm{D}_{1}$ or $\mathrm{D}_{5}$ receptors were expressed (data not shown), as reported above for DA cells in pure VTA cultures. Thus the presence of PFC cells did not alter the profile of DA receptors expressed by DA neurons. Next, we tested whether the presence of PFC cells altered GluR1
A
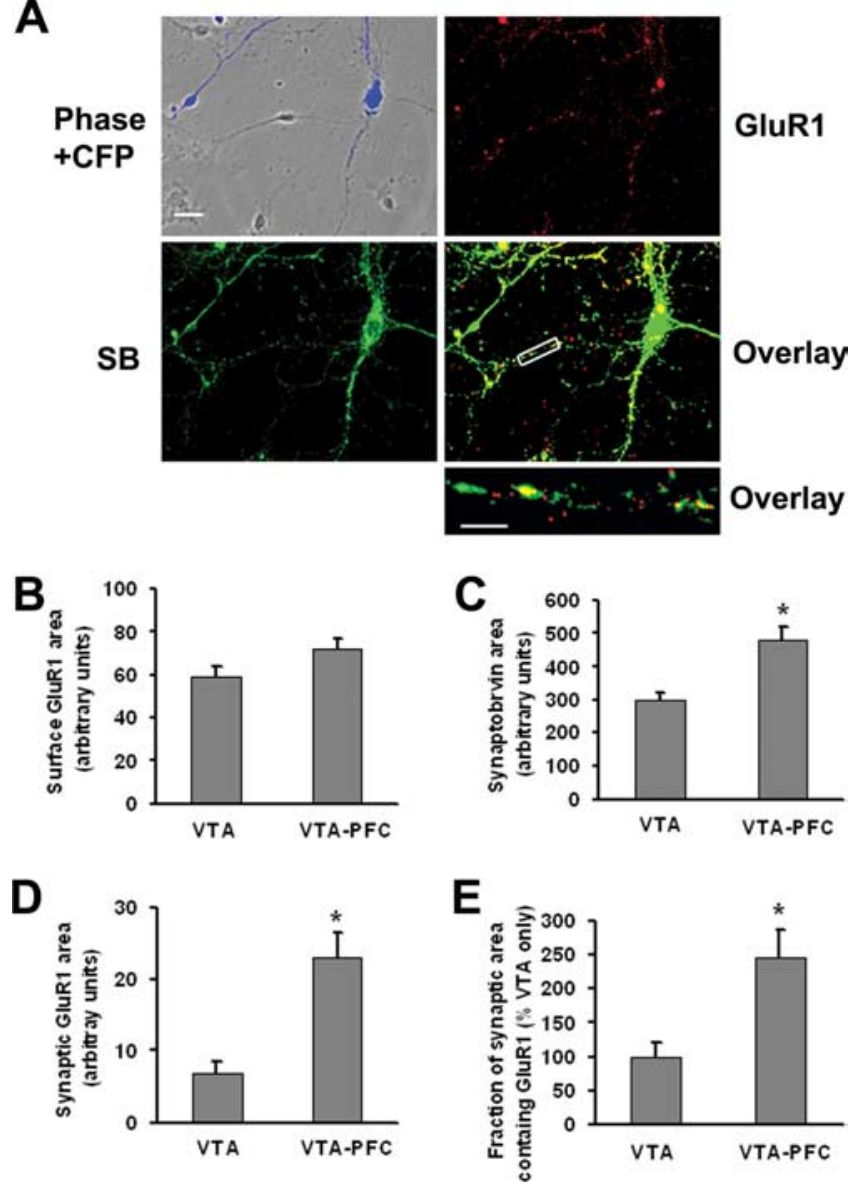

Figure 5. VTA-PFC cocultures exhibit higher synaptic GluR1 levels than pure VTA cultures. $A$, VTA and PFC neurons in VTA-PFC cocultures can be distinguished, enabling selective monitoring of AMPA receptors on VTA neurons, because only PFC cells express ECFP. Images show ECFP fluorescence (blue), GluR1 surface expression (red), synaptobrevin expression (SB, green), overlay of GluR1 and synaptobrevin staining (yellow), and a high-magnification overlay of a neuronal process for a putative DA neuron in VTA-PFC coculture. Scale bars: top four panels, $20 \mu \mathrm{m}$; bottom, $5 \mu \mathrm{m}$. $\boldsymbol{B}-\boldsymbol{E}$, Quantitative results comparing VTA cultures and VTA-PFC cocultures. $\boldsymbol{B}$, Surface GluR1 did not differ significantly between VTA cultures and VTA-PFC cocultures $(n=$ $19-20, t$ test, $p>0.05)$. However, synaptobrevin area (C), synaptic GluR1 area (D) and the fraction of synaptic area containing GluR1 $(\boldsymbol{E})$ were all significantly greater for DA neurons in VTA-PFC cocultures compared with VTA cultures $\left(n=19-20 ; t\right.$ tests, $\left.{ }^{*} p<0.05\right)$.

or synaptobrevin expression on VTA DA neurons. Cell surface GluR1 did not differ significantly between DA neurons in pure VTA cultures and VTA-PFC cocultures, although there was a trend toward an increase in the cocultures (Fig. 5B). However, coculture with PFC neurons significantly increased synaptobrevin expression, synaptic GluR1 area, and the fraction of synaptic area containing GluR1 (Figs. 5C-E). Nonsynaptic GluR1 area was not changed (data not shown). The existence of synaptic GluR1 on DA neurons in VTA-PFC cocultures establishes the coculture system as useful for studying the synaptic trafficking of AMPARs in VTA DA neurons.

$D_{1}$ receptor stimulation increases synaptic and nonsynaptic

GluR1 surface expression by DA neurons in VTA-PFC cocultures through a mechanism requiring glutamate transmission

To determine whether coculture with PFC neurons altered the response of VTA DA neurons to DA agonists, we re-examined the effect of quinpirole, SKF 81297 and DA in VTA-PFC cocultures. 

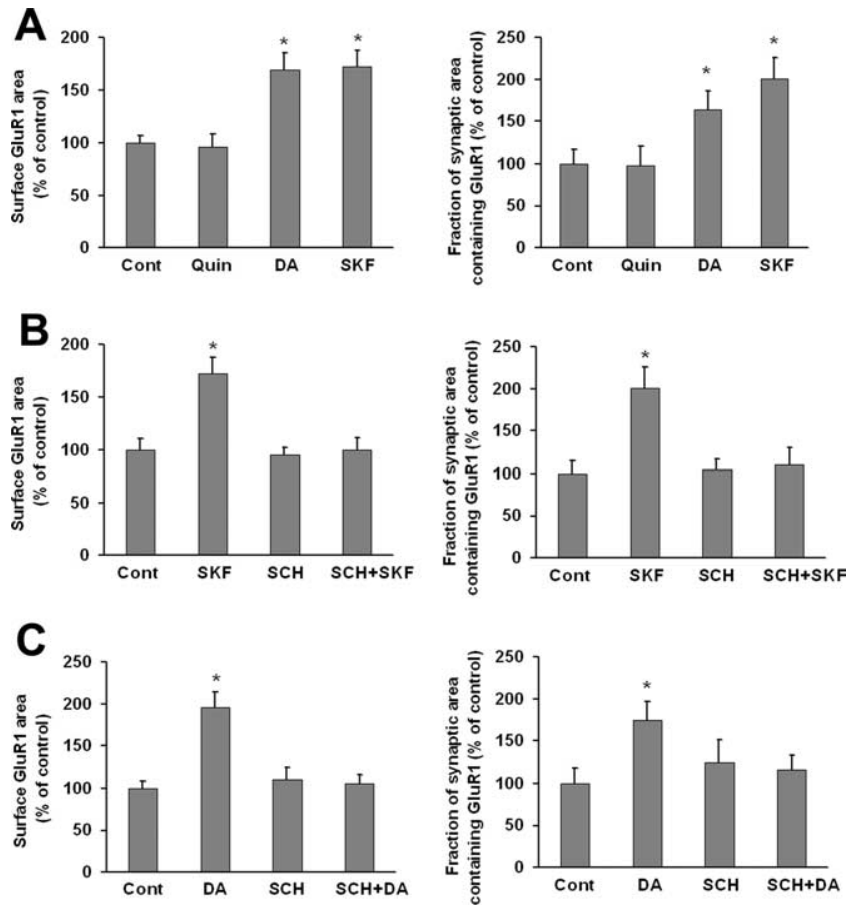

Figure 6. Brief $D_{1}$ receptor stimulation increases surface and synaptic GluR1 expression by DA neurons in VTA-PFC cocultures. A, VTA-PFC cocultures were treated with media (control group), the $\mathrm{D}_{2}$ agonist quinpirole (Quin; $1 \mu \mathrm{m}, 10 \mathrm{~min}$ ), $\mathrm{DA}\left(1 \mu \mathrm{m}, 10 \mathrm{~min}\right.$ ), or the $\mathrm{D}_{1}$ agonist SKF 81297 (SKF; $1 \mu \mathrm{M}, 10 \mathrm{~min}$ ). Both DA and SKF 81297 significantly increased surface GluR1 area and GluR1 synaptic incorporation compared with the control group ( $n=18-24$; Dunn's test, ${ }^{*} p<0.05$ ), whereas quinpirole had no effect on either measure (ANOVA, $p>0.05$ ). DA and SKF 81297 also increased nonsynaptic GluR1 (data not shown). $\boldsymbol{B}$, VTA-PFC cocultures were treated with media, SKF 81297 (1 $\mu \mathrm{m}, 10 \mathrm{~min}$ ), SCH 23390 (SCH, $10 \mu \mathrm{m}, 10 \mathrm{~min}$ ), or SCH + SKF (after 5 min preincubation with SCH 23390, SKF 81297 was added for 10 min). SCH 23390 alone had no effect on surface GluR1 area or GluR1 synaptic incorporation, but completely blocked the effect of SKF 81297 on these measures ( $n=19-24$; Dunn's test, $\left.{ }^{*} p<0.05\right)$. C, VTA-PFC cocultures were treated with media, DA (1 $\mu \mathrm{M}, 10 \mathrm{~min}$ ), SCH 23390 (10 $\mu \mathrm{M}, 10 \mathrm{~min}$ ), or SCH+DA (after 5 min preincubation with SCH 23390, DA was added for $10 \mathrm{~min}$ ). SCH 23390 alone had no effect on surface GluR1 area or GluR1 synaptic incorporation, but completely blocked the effect of DA on these measures ( $n=18-19$; Dunn's test, ${ }^{*} p<0.05$ ).

Whereas quinpirole had no effect on GluR1 distribution in DA neurons, DA (1 $\mu \mathrm{M}, 10 \mathrm{~min})$ and SKF $81297(1 \mu \mathrm{M}, 10 \mathrm{~min})$ significantly increased surface GluR1 area and the fraction of synaptic area containing GluR1 (Fig. 6A). Nonsynaptic GluR1 area also increased (data not shown). The $\mathrm{D}_{1}$ receptor antagonist SCH $23390(10 \mu \mathrm{M})$ completely blocked the effect of SKF 81297 or DA on surface and synaptic GluR1 area when added 5 min before each drug (Fig. 6B,C), as well as the effect of SKF 81297 or DA on nonsynaptic GluR1 area (data not shown). SCH 23390 had no effect when given alone. As $\mathrm{D}_{1}$ receptor stimulation did not affect GluR1 distribution in pure VTA cultures (Fig. 3), these results suggest that DA or SKF 81297 acted indirectly through $\mathrm{D}_{1}$ receptors on PFC neurons to influence GluR1 distribution on DA neurons. If this is the case, it is possible that glutamate transmission from PFC neurons to DA neurons conveyed the signal for upregulation of AMPAR surface and synaptic expression. To test this, the NMDA receptor antagonist APV $(50 \mu \mathrm{M})$ was added 5 min before SKF 81297 ( $1 \mu \mathrm{M}, 10 \mathrm{~min})$. APV itself had no effect on surface GluR1 or the fraction of synaptic area containing GluR1, but completely blocked the effect of SKF 81297 (Fig. 7). CNQX $(20 \mu \mathrm{M})$, a non-NMDA receptor antagonist, also inhibited the effect of SKF 81297, as did the combination of APV + CNQX (Fig. 7).
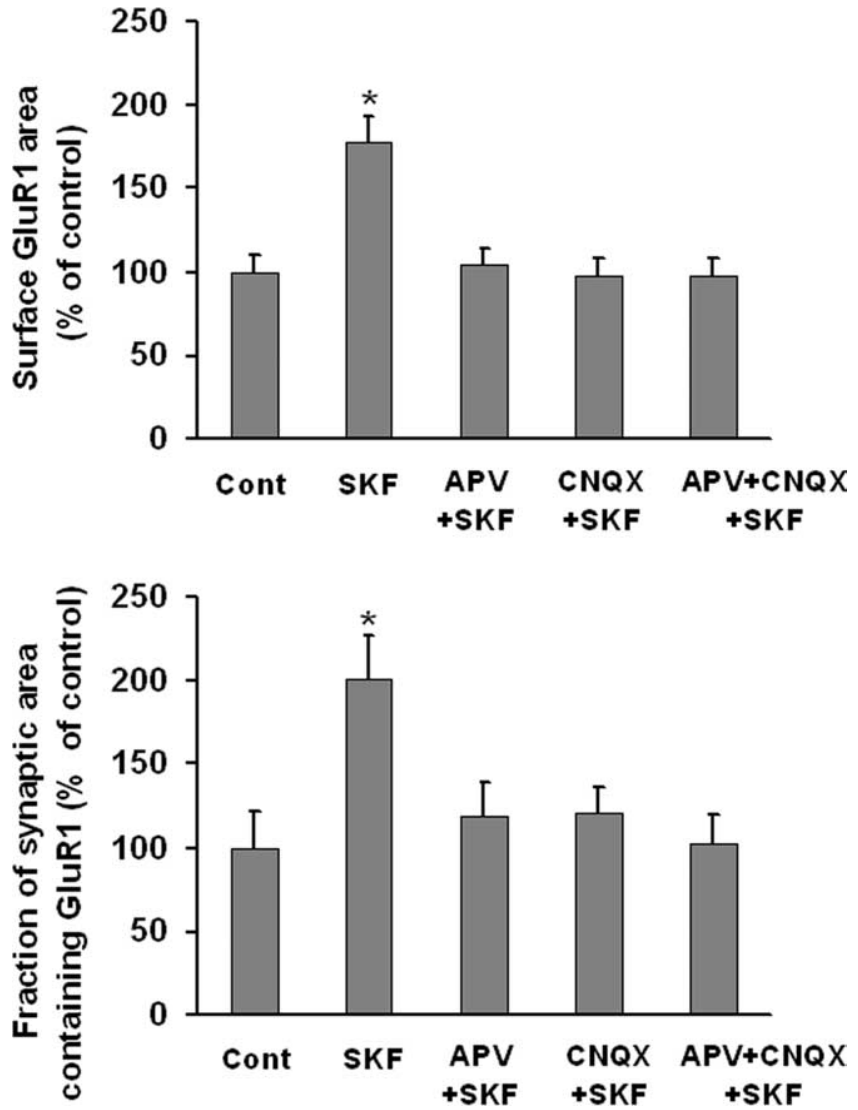

Figure 7. Glutamate transmission is required for the $D_{1}$ receptor-induced increase in surface and synaptic GluR1 expression by DA neurons in VTA-PFC cocultures. VTA-PFC cocultures were treated with media (control group), SKF 81297 (1 $\mu \mathrm{M}, 10 \mathrm{~min}$ ), the NMDA receptor antagonist APV and SKF 81297 (APV+SKF), the non-NMDA receptor antagonist CNQX and SKF 81297 (CNQX + SKF), or APV + CNQX + SKF. In the latter three groups, cocultures were incubated with antagonist(s) for 5 min and then SKF 81297 was added for $10 \mathrm{~min}$. APV or CNQX completely blocked the effect of SKF 81297 ( $n=19-24$; Dunn's test, ${ }^{*} p<0.05$ ).

Prolonged DA treatment of VTA-PFC cocultures mimics the effect of cocaine injection in vivo

In mice or rats, a single systemic cocaine injection $(15 \mathrm{mg} / \mathrm{kg})$ produced an increase in the AMPA/NMDA ratio in DA neurons recorded in VTA slices that was detectable $24 \mathrm{~h}$ or $5 \mathrm{~d}$ later, but not $10 \mathrm{~d}$ later; this was attributed to increased AMPAR synaptic insertion (Ungless et al., 2001; Saal et al., 2003; Borgland et al., 2004; Dong et al., 2004; Liu et al., 2005; Bellone and Luscher, 2006). We wondered whether we could mimic this effect by treating VTA-PFC cocultures with DA. In experiments described in preceding sections, we used a short DA incubation time (10 min) (Figs. 6, 7). Here, we used a longer incubation time ( $1 \mathrm{~h}$ ) to better reproduce the duration of elevation of extracellular DA levels in the rat VTA after injection of $15 \mathrm{mg} / \mathrm{kg}$ cocaine (Kalivas and Duffy, 1993). After the $1 \mathrm{~h}$ incubation period, cocultures were returned to normal media for recovery periods $(\mathrm{R})$ of $0,2,6$, and $24 \mathrm{~h}$. Whereas $10 \mathrm{~min}$ of incubation with DA rapidly elevated surface GluR1 levels (Fig. 6), the $1 \mathrm{~h}$ incubation with DA had no immediate effect (Fig. 8). However, after 24 h of recovery, DAtreated cultures exhibited a significant increase in GluR1 surface expression (Fig. $8 \mathrm{~B}$ ). The additional surface receptors were located in synapses because synaptic GluR1 area and the fraction of synaptic area containing GluR1 were increased, whereas nonsynaptic GluR1 area was not (Figs. $8 C-E$ ). We conclude that DA treatment of VTA-PFC cocultures reproduces, at least to some 


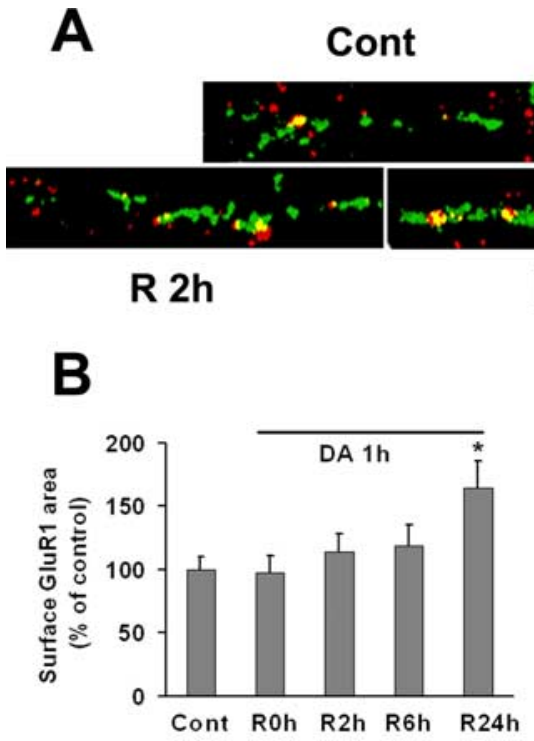

D

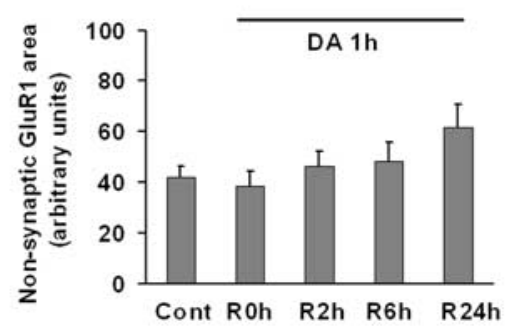

R Oh

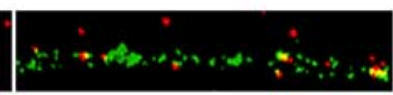

$\therefore$

R 6h

R 24h

C

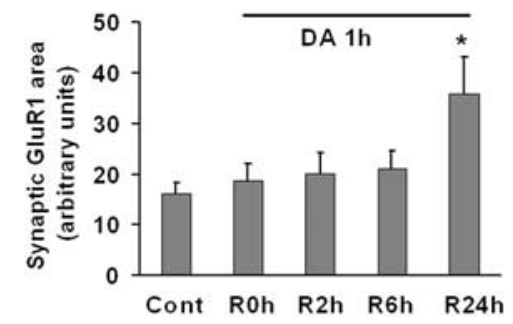

E

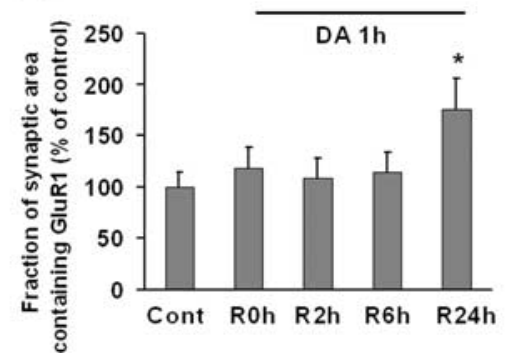

Figure 8. GluR1 surface and synaptic expression by DA neurons is increased $24 \mathrm{~h}$ after prolonged $(1 \mathrm{~h})$ incubation with DA. VTA-PFC cocultures were treated with $1 \mu \mathrm{m}$ DA or media for $1 \mathrm{~h}$ and then allowed to recover in media for $0 \mathrm{~h}(\mathrm{RO} h), 2 \mathrm{~h}(\mathrm{R} 2 \mathrm{~h}), 6 \mathrm{~h}$ (R6 h), or $24 \mathrm{~h}$ (R24 h). A, Representative images show overlay of surface GluR1 (red) and synaptobrevin (green) staining after different recovery times. Scale bar, $5 \mu \mathrm{m}$. $\boldsymbol{B}-\boldsymbol{E}$, Quantification of surface GluR1 staining $(\boldsymbol{B})$, synaptic GluR1 area $(\boldsymbol{C})$, nonsynaptic GluR1 area $(\boldsymbol{D})$, and the portion of synaptic area containing GluR1 $(\boldsymbol{E})$. After $24 \mathrm{~h}$ recovery, all measures except nonsynaptic GluR1 area were significantly increased $\left(n=20-23\right.$; Dunn's test, $\left.{ }^{*} p<0.05\right)$.

extent, cocaine-induced plasticity at excitatory synapses in the VTA. It is puzzling that synaptic GluR1 required $>6 \mathrm{~h}$ to increase after $1 \mathrm{~h}$ of incubation with DA (Fig. 8) whereas it was elevated immediately after $10 \mathrm{~min}$ of incubation with DA (Fig. 6). The delay may reflect a consequence of prolonged DA receptor activation that temporarily opposes AMPAR upregulation.

We extended this analysis by comparing the effect of $10 \mathrm{~min}$ and $1 \mathrm{~h}$ incubations with DA on GluR2 surface and synaptic expression by DA neurons in VTA-PFC cocultures. Cells examined immediately after brief DA treatment ( $1 \mu \mathrm{M}, 10 \mathrm{~min})$ exhibited increased surface and synaptic GluR2 expression, and this effect was blocked by the $\mathrm{D}_{1}$ antagonist SCH 23390 (Fig. 9A). Nonsynaptic GluR2 surface expression was also increased (data not shown). These findings parallel the results obtained for GluR1 after the same DA treatment (Fig. 6) and suggest that GluR1/2-containing AMPARs respond to brief $\mathrm{D}_{1}$ receptor stimulation. In contrast, prolonged DA treatment $(1 \mathrm{~h})$ had no effect on GluR2 surface or synaptic expression after 0 or $24 \mathrm{~h}$ of recovery (Fig. 9B). Nonsynaptic GluR2 expression was also unaffected (data not shown). Because synaptic GluR1 was increased after 24 h of recovery (Fig. 8), these results suggested increased synaptic expression of GluR2-lacking AMPARs as a result of prolonged DA treatment.
AMPA receptor subunit composition in VTA DA neurons

Although our results (above) and others (see Discussion) suggest that AMPARs of different subunit composition respond to particular treatments with DA agonists or cocaine, the subunit composition of AMPARs in VTA DA neurons has not been systematically evaluated. We addressed this problem by quantifying colocalization of surface-expressed GluR1-3 as determined from live cell labeling with antibodies recognizing the extracellular epitopes of these subunits. GluR4 was not examined because antibody to its extracellular domain is not available and because GluR4 was not detected in $\mathrm{TH}^{+}$cells of the rat substantia nigra pars compacta (Albers et al., 1999) or VTA (Chen et al., 2001). Colocalization was assessed exclusively for putative DA neurons, based on morphological criteria described above. Although we report quantitative results below, it is important to recognize that the accuracy of our measurements is limited by two factors. First, because antibodies differ in affinity for their target, staining with different antibodies cannot be directly compared. Second, we do not know how many AMPARs must be present in a puncta for it to exceed our threshold for detection; thus it is possible that we failed to detect some AMPAR subunits. Nevertheless, our results provide a useful estimate of the AMPAR populations present in our cultures.

We began by examining AMPAR subunit colocalization in pure VTA cultures. We analyzed 21 cells from VTA cultures double-labeled for GluR1 and GluR2, and 21 cells from VTA cultures double-labeled for GluR1 and GluR3. We found that $49 \pm 3 \%$ of total GluR1 staining area colocalized with GluR2, while $8 \pm 1 \%$ colocalized with GluR3, suggesting a significant number of GluR1/2 receptors and a smaller population of GluR1/3 receptors. The remainder of GluR1 staining ( $\sim 40 \%$ of total GluR1 staining) is likely to be present in homomeric GluR1 receptors. $\sim 45 \pm 4 \%$ of the total GluR2 staining area colocalized with GluR1, further supporting the existence of a substantial number of GluR $1 / 2$ receptors. $\sim 14 \pm 3 \%$ of the total GluR3 staining colocalized with GluR1, further supporting the existence of a small pool of GluR1/3 receptors, and suggesting that most GluR3 is present in GluR2/3 receptors rather than GluR1/3 receptors. We could not evaluate GluR2/3 receptors directly, because we could not obtain double labeling results for GluR2 and GluR3 that were satisfactory for quantitative analysis. Overall, these results suggest that DA neurons in pure VTA culture have a substantial number of GluR1/2 receptors, GluR2/3 receptors, and GluR2-lacking receptors that are mainly homomeric GluR1 but also GluR1/3. GluR2-lacking receptors exhibit higher conductance, permeability to $\mathrm{Ca}^{2+}$, and inward rectification due to voltagedependent block by polyamines (Cull-Candy et al., 2006).

Next, we performed parallel studies for DA neurons in VTAPFC cocultures. In light of evidence that AMPAR subunit com- 
position may be altered by DA (Fig. 9) or cocaine (see Discussion), we examined colocalization of surface GluR1-3 in two experimental groups: cocultures incubated for $1 \mathrm{~h}$ with media and stained $24 \mathrm{~h}$ later (controls), and cocultures incubated for $1 \mathrm{~h}$ with DA $(1 \mu \mathrm{M})$ and stained $24 \mathrm{~h}$ later. For control and DA groups, respectively, we analyzed 23 and 18 cells in cultures double-labeled for GluR1 and GluR2, and 21 and 18 cells in cultures double-labeled for GluR1 and GluR3. Examples of double-staining in VTA-PFC cocultures are shown in Figure $10 \mathrm{~A}$. Quantification of results from control cultures indicated a substantial number of GluR1/2containing receptors, a lower number of GluR1/3-containing receptors, and some GluR1 staining $(\sim 40 \%$ of total $)$ that did not colocalize with other subunits (Figs. $10 \mathrm{~A}, \mathrm{C})$, similar to results obtained for pure VTA cultures (above). After a $1 \mathrm{~h}$ incubation with DA, total surface GluR1 expression was increased (Figs. $10 A, B$ ), confirming results shown in Figure 8. Surface GluR3 was also increased, but GluR2 was not (Figs. $10 A, B$ ), which is consistent with results shown in Figure 9B. Furthermore, DA treatment produced a significant increase in colocalized surface GluR1 and GluR3 area, suggesting additional GluR1/ 3 -containing receptors (Fig. 10A,C), and in the portion of surface GluR1 staining that did not colocalize with GluR2 (GluR2-lacking GluR1-containing AMPARs) (Fig. 10D). These results suggest an increase in GluR1/3 and/or homomeric GluR1 receptors on the surface of VTA DA neurons $24 \mathrm{~h}$ after DA exposure. We do not interpret our results to indicate increased levels of homomeric GluR3 receptors because there is no evidence that this type of AMPAR exists in neurons.

We could not evaluate AMPAR subunit colocalization with a synaptic marker in the experiments shown in Figure 10 because all available fluorophores were used (cyan for PFC cells, and red and green for labeling AMPAR subunit pairs). However, results shown in Figure 9, which evaluated colocalization of GluR1 or GluR2 with a synaptic marker, indicate that synaptic GluR1 but not GluR2 increases in cells examined $24 \mathrm{~h}$ after $1 \mathrm{~h}$ of incubation with DA. Combined with data on GluR1-3 colocalization shown in Figure 10, these results indicate that GluR2-lacking AMPARs increase at synaptic sites after prolonged incubation with DA.

\section{Discussion}

\section{Characterization of DA neurons in pure VTA cultures}

The properties of DA neurons in midbrain cultures have been described previously (di Porzio et al., 1980; Heyer, 1984; Chiodo and Kapatos, 1987; Silva et al., 1988; Rayport et al., 1992; Gross et al., 1999; Lotharius et al., 1999), but no previous studies have characterized DA or AMPAR surface expression. As expected, robust $\mathrm{D}_{2}$ receptor surface expression was found. $\mathrm{D}_{2}$ receptors serve as autoreceptors (Wolf and Roth, 1987) and, within the VTA, only DA neurons express $\mathrm{D}_{2}$ receptors (Meador-Woodruff et al., 1989; Sesack et al., 1994). No $D_{1}$ or $D_{5}$ receptors were found on the surface of VTA DA neurons in our cultures, indicating that if they exist, levels are very low compared with $\mathrm{D}_{2}$ receptors. The AMPAR subunit GluR1 was also detected on the surface of VTA DA neurons. Most surface GluR1 was extrasynaptic, although a small amount $(\sim 2 \%)$ of the synaptic marker synaptobrevin colocalized with GluR1. This may reflect the presence of glutamatereleasing neurons in the VTA (Sulzer and Rayport, 2000; Dal Bo et al., 2004; Kawano et al., 2006; Yamaguchi et al., 2007).

We estimated the subunit composition of cell surface AMPARs on VTA DA neurons by examining colocalization of GluR1-3 surface staining. Our results suggest that VTA DA neurons have on their cell surface a substantial number of GluR1/2 receptors and some GluR2/3 receptors, as well as GluR2-lacking receptors (homomeric GluR1 and GluR1/3). As noted in Results, our colocalization data provide an estimate of subunit composition, rather than a definitive determination, because of technical concerns related to differences in antibody affinity and the possibility of receptor subunit expression at levels below our threshold of detection. Our results are consistent with many studies that detected GluR1-3 in the rat midbrain (Petralia and Wenthold, 1992; Sato et al., 1993; Jakowec et al., 1998; Albers et al., 1999; Chatha et al., 2000; Chen et al., 2001; Lu et al., 2002). The expression of GluR2-lacking AMPARs by VTA DA neurons is more controversial (see below). 

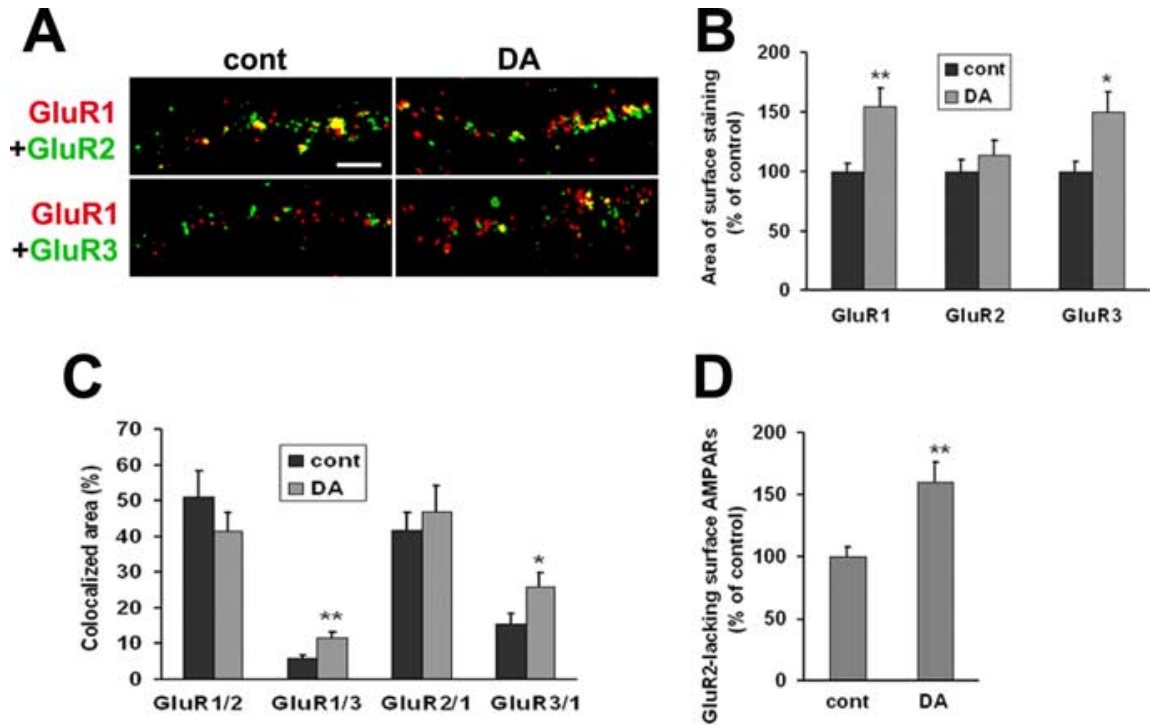

Figure 10. Surface expression of GluR2-lacking receptors is increased after $24 \mathrm{~h}$ of recovery from prolonged DA exposure. $A, \mathrm{In}$ VTA-PFC cocultures, cells were treated with media [control (cont)] or DA $(1 \mu \mathrm{m})$ for $1 \mathrm{~h}$. After $24 \mathrm{~h}$ of recovery, live cells were double labeled with antibodies recognizing the extracellular N-terminal domains of GluR1 and GluR2 or GluR1 and GluR3. Images depict surface expression of GluR1 (red), GluR2 or GluR3 (green), and overlays showing area of colocalization (yellow). Scale bar, $5 \mu \mathrm{m}$. $B$, After $24 \mathrm{~h}$ of recovery from DA exposure $(1 \mathrm{~h})$, the areas of surface staining for GluR1 and GluR3 were increased, whereas GluR2 staining was not altered $\left(n=18-23 ; t\right.$ test, $\left.{ }^{*} p<0.05,{ }^{* *} p<0.01\right)$. C, Area of colocalization for different pairs of AMPA receptor subunits. The labels on the $x$-axis indicate the pair analyzed. For example, GluR1/2 refers to the percentage of total GluR1 staining that is colocalized with GluR2, and so forth. The area of colocalized surface staining for GluR1 and GluR3 (GluR1/3 and GluR3/1) was increased after DA treatment $\left(n=18-23 ; t\right.$ test, $\left.{ }^{*} p<0.05,{ }^{* *} p<0.01\right)$, whereas colocalization of GluR1 and GluR2 (GluR1/2 and GluR2/1) was not $(n=18-23 ; t$ test, $p>0.05)$. D , The area of GluR1 surface staining that was not colocalized with GluR2 was used as a measure of surface expression of putative GluR2-lacking AMPA receptors. This measure was increased after DA treatment compared with the control group $\left(n=18-23 ; t\right.$ test, $\left.{ }^{* *} p<0.01\right)$.

DA agonists did not alter GluR1 surface expression by DA neurons in pure VTA cultures. However, PKA activation in pure VTA cultures increased cell surface GluR1 levels. This is consistent with results in many brain regions indicating that PKA promotes AMPAR surface expression, although additional mechanisms involving CaMKII $\left(\mathrm{Ca}^{2+} /\right.$ calmodulin-dependent protein kinase II) must be engaged for AMPARs to enter synapses (Esteban et al., 2003 Oh et al., 2006; Gao et al., 2006; Man et al., 2007). In contrast, PKA activation in VTA slices prepared from 15- to 21-d-old rats produced a form of LTD involving decreased cell surface AMPARs as measured by biotinylation (Gutlerner et al., 2002). The effect of PKA activation may change during development.

\section{Excitatory synaptic input to DA neurons is restored in VTA-PFC cocultures}

Glutamate afferents to the VTA play an important role in controlling the firing pattern of DA neurons (Kalivas, 1993; White, 1996; Overton and Clark, 1997) and in synaptic plasticity related to addiction (Kauer, 2004; Wolf et al., 2004). These afferents arise from multiple areas including the mesopontine tegmentum and PFC (Tzschentke and Schmidt, 2000; Omelchenko and Sesack, 2007). To study AMPAR trafficking at excitatory synapses onto DA neurons, we developed a VTA-PFC coculture system that restores excitatory input to VTA neurons while preserving the ability to distinguish VTA and PFC cells. The presence of PFC neurons produced a threefold increase in synaptic GluR1 expression, compared with pure VTA cultures, consistent with previous results showing that the appearance of excitatory synapses in cultured neurons depends on excitatory afferent activity (Segal et al., 2003).
Brief stimulation of $D_{1}$ receptors on PFC neurons increases synaptic and nonsynaptic GluR1 and GluR2 on DA neurons in coculture

In VTA-PFC cocultures, brief (10 min) application of DA or the $\mathrm{D}_{1}$ agonist SKF 81297 increased synaptic and nonsynaptic GluR1 surface expression on DA neurons. Parallel results were obtained for GluR2, suggesting an increase in GluR1/2containing AMPARs in response to brief $\mathrm{D}_{1}$ receptor stimulation. Based on lack of effect of DA agonists in pure VTA cultures, we concluded that DA and SKF 81297 were acting indirectly through $D_{1}$ receptors on PFC neurons. PFC neurons would then convey a signal to VTA DA neurons (either directly, or via effects on other cell types in the VTA), leading to AMPAR upregulation on the DA neurons. This signal could involve altered glutamate transmission between PFC and VTA neurons. Supporting this hypothesis, the effects of DA and SKF 81297 on GluR1 surface and synaptic expression by DA neurons were blocked by NMDA or non-NMDA receptor antagonists.

Our studies do not address the mechanism by which $\mathrm{D}_{1}$ receptor stimulation activates glutamate transmission onto VTA DA neurons, but in vivo and brain slice studies support the hypothesis that $\mathrm{D}_{1}$ receptors act directly on PFC neurons to increase their excitability and increase glutamate levels in their target regions (Park et al., 2002; Dong and White, 2003). Interestingly, bath application of amphetamine to VTA slices failed to increase the AMPA/NMDA ratio, which could indicate a locus of action outside the VTA (perhaps PFC) but might also indicate a requirement for normal excitatory synaptic transmission, which is absent in the slice preparation (Faleiro et al., 2004). Alternatively, $\mathrm{D}_{1}$ receptors on glutamate terminals in the VTA may facilitate glutamate release, increasing AMPAR surface and synaptic expression by activity-dependent mechanisms related to those operative in LTP. However, there is disagreement about whether the immediate effect of local $D_{1}$ receptor stimulation is to inhibit or increase VTA glutamate release (Kalivas and Duffy, 1995; Wolf and Xue, 1998; Schilström et al., 2006).

We and others have shown previously that $\mathrm{D}_{1}$ receptor stimulation increases AMPAR surface expression in principal cells of the nucleus accumbens, PFC, and hippocampus studied in primary culture (see Introduction). All of these cells receive convergent DA and glutamate inputs, so we hypothesized that $\mathrm{D}_{1}$ receptors activate signaling pathways in the postsynaptic neuron that modulate AMPAR trafficking at its nearby glutamate synapses. This cannot occur in VTA DA neurons in our cultures, because these neurons lack $\mathrm{D}_{1}$-class receptors. However, VTA DA neurons in adult rats express $D_{5}$ receptors (Ciliax et al., 2000; Khan et al., 2000). Cocaine, by activating $D_{1} / D_{5}$ receptors and postsynaptic PKA signaling in VTA DA neurons, potentiates NMDA receptor currents in young rats (P21-P29) (Schilström et al., 2006). This may facilitate LTP after in vivo cocaine exposure. Cocaine may also facilitate LTP by reducing GABA transmission in the VTA (Liu et al., 2005). 


\section{Relevance to in vivo plasticity in the VTA produced by cocaine}

The development of behavioral sensitization involves LTP at excitatory synapses between glutamate terminals and VTA DA neurons, measured as an increase in the AMPA/NMDA ratio that is believed to result from synaptic insertion of AMPARs. An in vitro model for this phenomenon would be valuable. Here we show that a $1 \mathrm{~h}$ exposure to DA, mimicking the duration of elevation of VTA DA levels after systemic cocaine, produced an increase in synaptic GluR1 but not GluR2 expression that was detected $24 \mathrm{~h}$ later. We extended these findings by investigating AMPAR subunit composition, based on colocalization of surface-expressed GluR1-3. In control VTA-PFC cocultures, colocalization was similar to pure VTA cultures. After a $1 \mathrm{~h}$ DA exposure and $24 \mathrm{~h}$ of recovery, we found increased surface expression of GluR1 and GluR3, but not GluR2, and increased area of GluR1/3 colocalization, suggesting formation of GluR2-lacking receptors. This is consistent with our findings of increased surface expression of GluR1 (Boudreau and Wolf, 2005) but not GluR2 (Boudreau and Wolf, unpublished observations) in the rat VTA $24 \mathrm{~h}$ after a single cocaine injection. A role for GluR2-lacking receptors in VTA plasticity was originally suggested based on immunoblotting studies showing increased GluR1 in the VTA of cocaine-exposed rats (Carlezon and Nestler, 2002). This could be related to our findings of increased surface expression. Electrophysiological studies also support a role for GluR2-lacking receptors in VTA plasticity. Bellone and Luscher (2005) detected a substantial complement of GluR2-lacking receptors in VTA DA neurons of naive rats (P15-P21), which internalized during LTD. Faleiro et al. (2004) did not detect GluR2-lacking receptors in VTA DA cells of naive P15-P18 rats. GluR2-lacking receptors were not detected in VTA DA cells of naive mice (Thomas et al., 2000; Bellone and Luscher, 2006) but were added to synapses after cocaine injection (Bellone and Luscher, 2006). Different species, ages, stress levels (which also affect VTA AMPA/NMDA ratios) (Saal et al., 2003), and methods may contribute to these discrepancies.

\section{Conclusions}

DA agonists do not alter AMPAR distribution in pure VTA cultures. However, in VTA-PFC cocultures, brief $\mathrm{D}_{1}$ receptor stimulation activates glutamate transmission between PFC and VTA neurons, leading to increased synaptic and nonsynaptic GluR1 and GluR2 surface expression by VTA DA neurons. Prolonged incubation with DA, reproducing the elevation of extracellular DA levels produced by systemic cocaine injection, leads to elevated AMPAR synaptic expression $24 \mathrm{~h}$ after DA exposure. The new receptors may contain GluR1 and GluR3. This in vitro model extends our understanding of AMPAR plasticity in the VTA produced by cocaine exposure.

\section{References}

Albers DS, Weiss SW, Iadarola MJ, Standaert DG (1999) Immunohistochemical localization of N-methyl-D-aspartate and $\alpha$-amino-3-hydroxy5-methyl-4-isoxazolepropionate receptor subunits in the substantia nigra pars compacta of the rat. Neuroscience 89:209-220.

Bellone C, Luscher C (2005) mGluRs induce a long-term depression in the ventral tegmental area that involves a switch of the subunit composition of AMPA receptors. Eur J Neurosci 21:1280-1288.

Bellone C, Luscher C (2006) Cocaine triggered AMPA receptor redistribution is reversed in vivo by mGluR-dependent long-term depression. Nat Neurosci 9:636-641.

Bentivoglio M, Morelli M (2005) The organization and circuits of mesencephalic dopaminergic neurons and the distribution of dopamine receptors in the brain. In: Handbook of chemical neuroanatomy, Vol XXI, Dopa- mine (Dunnett SB, Bentivoglio M, Björklund A, Hökfelt T, eds), pp 1-106. Amsterdam: Elsevier.

Borgland SL, Makenka RC, Bonci A (2004) Acute and chronic cocaineinduced potentiation of synaptic strength in the ventral tegmental area: electrophysiological and behavioral correlates in individual rats. J Neurosci 24:7482-7490.

Boudreau AC, Wolf ME (2005) Behavioral sensitization to cocaine is associated with increased AMPA receptor surface expression in the nucleus accumbens. J Neurosci 25:9144-9151.

Bredt DS, Nicoll RA (2003) AMPA receptor trafficking at excitatory synapses. Neuron 40:361-379.

Carlezon Jr WA, Nestler EJ (2002) Elevated levels of GluR1 in the midbrain: a trigger for sensitization to drugs of abuse? Trends Neurosci 25:610-615.

Carr DB, Sesack SR (2000) Projections from the rat prefrontal cortex to the ventral tegmental area: target specificity in the synaptic associations with mesoaccumbens and mesocortical neurons. J Neurosci 20:3864-3873.

Chao SZ, Lu WX, Lee HK, Huganir RL, Wolf ME (2002a) D1 dopamine receptor stimulation increases GluR1 phosphorylation in postnatal nucleus accumbens cultures. J Neurochem 81:984-992.

Chao SZ, Ariano MA, Peterson DA, Wolf ME (2002b) D1 dopamine receptor stimulation increases GluR1 surface expression in nucleus accumbens neurons. J Neurochem 83:704-712.

Chatha BT, Bernard V, Streit P, Bolam JP (2000) Synaptic localization of ionotropic glutamate receptors in the rat substantia nigra. Neuroscience 101:1037-1051

Chen LW, Wei LC, Lang B, Ju G, Chan YS (2001) Differential expression of AMPA receptor subunits in dopamine neurons of the rat brain: a double immunocytochemical study. Neuroscience 106:149-160.

Chiodo LA, Kapatos G (1987) Mesencephalic neurons in primary culture: immunohistochemistry and membrane physiology. In: Neurophysiology of dopaminergic systems-current status and clinical perspectives (Chiodo LA, Freeman AS, eds), pp 67-91. Detroit: Lakeshore.

Ciliax BJ, Nash N, Heilman C, Sunahara R, Hartney A, Tiberi M, Rye DB, Caron MG, Niznik HB, Levey AI (2000) Dopamine D5 receptor immunolocalization in rat and monkey brain. Synapse 37:125-145.

Collingridge GL, Isaac JT, Wang YT (2004) Receptor trafficking and synaptic plasticity. Nat Rev Neurosci 5:952-962.

Cull-Candy S, Kelly L, Farrant M (2006) Regulation of $\mathrm{Ca}^{2+}$-permeable AMPA receptors: synaptic plasticity and beyond. Curr Opin Neurobiol 16:288-297.

Dal Bo G, St-Gelais F, Danik M, Williams S, Cotton M, Trudeau LE (2004) Dopamine neurons in culture express VGLUT2 explaining their capacity to release glutamate at synapses in addition to dopamine. J Neurochem 88:1398-1405.

Derkach VA, Oh MC, Guire ES, Soderling TR (2007) Regulatory mechanisms of AMPA receptors in synaptic plasticity. Nat Rev Neurosci 8:101-113.

di Porzio U, Daguet MC, Glowinski J, Prochiantz A (1980) Effect of striatal cells on in vitro maturation of mesencephalic dopaminergic neurones grown in serum-free conditions. Nature 288:370-373.

Dong Y, White FJ (2003) Dopamine D1-class receptors selectively modulate a slowly inactivating potassium current in rat medial prefrontal cortex pyramidal neurons. J Neurosci 23:2686-2695.

Dong Y, Saal D, Thomas M, Faustr, Bonci A, Robinson T, Malenka RC (2004) Cocaine-induced potentiation of synaptic strength in dopamine neurons: Behavioral correlates in GluRA $(-/-)$ mice. Proc Natl Acad Sci USA 101:14282-14287.

Esteban JA, Shi SH, Wilson C, Nuriya M., Huganir RL, Malinow R (2003) PKA phosphorylation of AMPA receptor subunits controls synaptic trafficking underlying plasticity. Nat Neurosci 6:136-143.

Faleiro LJ, Jones S, Kauer JA (2004) Rapid synaptic plasticity of glutamatergic synapses on dopamine neurons in the ventral tegmental area in response to acute amphetamine injection. Neuropsychopharmacol 29:2115-2125.

Gao C, Sun X, Wolf ME (2006) Activation of D1 dopamine receptors increases surface expression of AMPA receptors and facilitates their synaptic incorporation in cultured hippocampal neurons. J Neurochem 98:1664-1677.

Geisler S, Derst C, Veh RW, Zahm DS (2007) Glutamatergic afferents of the ventral tegmental area in the rat. J Neurosci 27:5730-5743.

Grace AA, Onn S-P (1989) Morphology and electrophysiological properties of immunocytochemically identified rat dopamine neurons recorded in vitro. J Neurosci 9:3463-3481. 
Gross J, Ungethum U, Andreeva N, Heldt J, Gao J, Marschhausen G, Altmann T, Muller I, Husemann B, Andersson K (1999) Hypoxia during early developmental period induces long-term changes in the dopamine content and release in a mesencephalic cell culture. Neuroscience 92:699-704.

Gutlerner JL, Penick EC, Snyder EM, Kauer JA (2002) Novel protein kinase A-dependent long-term depression of excitatory synapses. Neuron 36:921-931.

Heyer EJ (1984) Electrophysiological study of mammalian neurons from ventral mesencephalon grown in primary dissociated cell culture. Brain Res 310:142-148.

Jakowec MW, Jackson-Lewis V, Chen X, Langston JW, Przedborski S (1998) The postnatal development of AMPA receptor subunits in the basal ganglia of the rat. Dev Neurosci 20:19-33.

Kalivas PW (1993) Neurotransmitter regulation of dopamine neurons in the ventral tegmental area. Brain Res Rev 18:75-113.

Kalivas PW, Duffy P (1993) Time course of extracellular dopamine and behavioral sensitization to cocaine. II. Dopamine perikarya. J Neurosci 13:276-284.

Kalivas PW, Duffy P (1995) D1 receptors modulate glutamate transmission in the ventral tegmental area. J Neurosci 15:5379-5388.

Kapatos G, Hirayama KA (1994) Comparison of the developing dopamine neuron phenotype in cultures of embryonic rat mesencephalon and hypothalamus. Neurochem Int 25:309-319.

Kauer JA (2004) Learning mechanisms in addiction: Synaptic plasticity in the ventral tegmental area as a result of exposure to drugs of abuse. Annu Rev Physiol 66:447-475.

Kawano M, Kawasaki A, Sakata-Haga H, Fukui Y, Kawano H, Nogami H, Hisano S (2006) Particular subpopulations of midbrain and hypothalamic dopamine neurons express vesicular glutamate transporter 2 in the rat brain. J Comp Neurol 498:581-592.

Khan ZU, Gutierrez A, Martin R, Penafiel A, Rivera A, de la Calle A (2000) Dopamine D5 receptors of rat and human brain. Neuroscience 100:689-699.

Liu QS, Pu L, Poo MM (2005) Repeated cocaine exposure in vivo facilitates LTP induction in midbrain dopamine neurons. Nature 437:1027-1031.

Lotharius J, Dugan LL, O'Malley KL (1999) Distinct mechanisms underlie neurotoxin-mediated cell death in cultured dopaminergic neurons. J Neurosci 19:1284-1293.

Lu W, Monteggia LM, Wolf ME (2002) Repeated administration of amphetamine or cocaine does not alter AMPA receptor subunit expression in the rat midbrain. Neuropsychopharmacol 26:1-13.

Malinow R, Malenka RC (2002) AMPA receptor trafficking and synaptic plasticity. Annu Rev Neurosci 25:103-126.

Man HY, Sekine-Aizawa Y, Huganir RL (2007) Regulation of $\alpha$-amino-3hydroxy-5-methyl-4-isoxazolepropionic acid receptor trafficking through PKA phosphorylation of the Glu receptor 1 subunit. Proc Natl Acad Sci USA 104:3579-3584.

Mangiavacchi S, Wolf ME (2004) D1 dopamine receptor stimulation increases the rate of AMPA receptor insertion onto the surface of cultured nucleus accumbens neurons through a pathway dependent on protein kinase A. J Neurochem 88:1261-1271.

Meador-Woodruff JH, Mansour A, Bunzow JR, Van Tol HH, Watson Jr SJ, Civelli O (1989) Distribution of D2 dopamine receptor mRNA in rat brain. Proc Natl Acad Sci USA 86:7625-7628.

Oh MC, Derkach VA, Guire ES, Soderling ER (2006) Extrasynaptic membrane trafficking regulated by GluR1 serine 845 phosphorylation primes AMPA receptors for LTP. J Biol Chem 281:752-758.

Omelchenko N, Sesack SR (2005) Laterodorsal tegmental projections to identified cell populations in the rat ventral tegmental area. J Comp Neurol 483:217-235.

Omelchenko N, Sesack SR (2007) Glutamate synaptic inputs to ventral tegmental area neurons in the rat derive primarily from subcortical sources. Neuroscience 146:1259-1274.

Overton PG, Clark D (1997) Burst firing in midbrain dopaminergic neurons. Brain Res Rev 25:312-334.

Park WK, Bari AA, Jey AR, Anderson SM, Spealman RD, Rowlett JK, Pierce RC (2002) Cocaine administered into the medial prefrontal cortex reinstates cocaine-seeking behavior by increasing AMPA receptor-mediated glutamate transmission in the nucleus accumbens. J Neurosci 22:2916-2925.

Petralia RS, Wenthold RJ (1992) Light and electron immunocytochemical localization of AMPA-selective glutamate receptors in the rat brain. J Comp Neurol 318:329-354.

Pu L, Liu QS, Poo MM (2006) BDNF-dependent synaptic sensitization in midbrain dopamine neurons after cocaine withdrawal. Nat Neurosci 9:605-607.

Rayport S, Sulzer D, Shi WX, Sawasdikosol S, Monaco J, Batson D, Rajendran G (1992) Identified postnatal mesolimbic dopamine neurons in culture: morphology and electrophysiology. J Neurosci 12:4264-4280.

Saal D, Dong Y, Bonci A, Malenka RC (2003) Drugs of abuse and stress trigger a common synaptic adaptation in dopamine neurons. Neuron 37:577-582.

Sato K, Kiyama H, Tohyama M (1993) The differential expression patterns of messenger RNAs encoding non-N-methyl-D-aspartate receptor subunits (GluR1-4) in the rat brain. Neuroscience 52:515-539.

Schilström B, Yaka R, Argilli E, Suvarna N, Schumann J, Chen BT, Carman M, Singh V, Mailliard WS, Ron D, Bonci A (2006) Cocaine enhances NMDA receptor-mediated currents in ventral tegmental area cells via dopamine D5 receptor-dependent redistribution of NMDA receptors. J Neurosci 26:8549-8558.

Schultz W (2007) Behavioral dopamine signals. Trends Neurosci 30:203-210.

Segal M, Greeberger V, Korkotian E (2003) Formation of dendritic spines in cultured striatal neurons depends on excitatory afferent activity. Eur J Neurosci 17:2573-2585.

Sesack SR, Aoki C, Pickel VM (1994) Ultrastructural localization of $\mathrm{D}_{2}$ receptor-like immunoreactivity in midbrain dopamine neurons and their striatal targets. J Neurosci 14:88-106.

Silva NL, Mariani AP, Harrison NL, Barker JL (1988) 5,7Dihydroxytryptamine identifies living dopaminergic neurons in mesencephalic cultures. Proc Natl Acad Sci USA 85:7346-7350.

Smith WB, Starck SR, Roberts RW, Schuman EM (2005) Dopaminergic stimulation of local protein synthesis enhances surface expression of GluR1 and synaptic transmission in hippocampal neurons. Neuron 45:765-779.

Sulzer D, Rayport S (2000) Dale's principle and glutamate corelease from ventral midbrain dopamine neurons. Amino Acids 19:45-52.

Sun X, Zhao Y, Wolf ME (2005) Dopamine receptor stimulation modulates AMPA receptor synaptic insertion in prefrontal cortex neurons. J Neurosci 25:7342-7351.

Thomas MJ, Malenka RC, Bonci A (2000) Modulation of long-term depression by dopamine in the mesolimbic system. J Neurosci 20:5581-5586.

Tzschentke TM, Schmidt WJ (2000) Functional relationship among medial prefrontal cortex, nucleus accumbens, and ventral tegmental area in locomotion and reward. Crit Rev Neurobiol 14:131-142.

Ungless MA, Whistler JL, Makenka RC, Bonci A (2001) Single cocaine exposure in vivo induces long-term potentiation in dopamine neurons. Nature 411:583-587.

White FJ (1996) Synaptic regulation of mesocorticolimbic dopamine neurons. Annu Rev Neurosci 19:405-436.

White FJ, Hu XT, Zhang XF, Wolf ME (1995) Repeated administration of cocaine or amphetamine alters neuronal responses to glutamate in the mesoaccumbens dopamine system. J Pharmacol Exp Ther 273:445-454.

Wolf ME (1998) The role of excitatory amino acids in behavioral sensitization to psychomotor stimulants. Prog Neurobiol 54:679-720.

Wolf ME, Roth RH (1987) Dopamine autoreceptors. In Structure and function of dopamine receptors, receptor biochemistry and methodology, $\mathrm{Vol}$ IX (Creese I, Fraser CM, eds), pp 45-96. New York, Alan R. Liss.

Wolf ME, Xue C-J (1998) Amphetamine and D1 receptor agonists produce biphasic effects on glutamate efflux in rat ventral tegmental area: Modification by repeated amphetamine administration. J Neurochem 70:198-209.

Wolf ME, Sun X, Mangiavacchi S, Chao SZ (2004) Psychomotor stimulants and neuronal plasticity. Neuropharmacology 47 [Suppl 1]:61-79.

Yamaguchi T, Sheen W, Morales M (2007) Glutamatergic neurons are present in the rat ventral tegmental area. Eur J Neurosci 25:106-118.

Yung K, Bolam J, Smith A, Hersch S, Ciliax B, Levey A (1995) Immunocytochemical localization of D1 and D2 dopamine receptors in the basal ganglia of the rat: light and electron microscopy. Neurosci 65:709-730.

Zhang XF, Hu XT, White FJ, Wolf ME (1997) Increased responsiveness of ventral tegmental area dopamine neurons to glutamate after repeated administration of cocaine or amphetamine is transient and selectively involves AMPA receptors. J Pharmacol Exp Ther 281:699-706. 